\title{
A NOTE ON JORDAN DERIVABLE LINEAR MAPS
}

\author{
Gregor Dolinar, Kan He, Bojan Kuzma and XiaOfei Qi
}

Abstract. Let $H$ be a complex Hilbert space and let $\delta$ be a linear map which is Jordan derivable at a given idempotent $P \in \mathrm{B}(H)$ in the sense that $\delta\left(A^{2}\right)=\delta(A) A+A \delta(A)$ holds for all $A$ with $A^{2}=P$. If $P$ has infinite rank and co-rank, then we prove that the restriction of $\delta$ to $\mathrm{B}(\operatorname{Im} P)$ is an inner derivation and the restriction to $\mathrm{B}(\operatorname{Ker} P)$ is a sum of inner derivation and multiplication by a scalar. We give an example that this is not necessarily true when rank and co-rank of $P$ are finite.

Mathematics subject classification (2010): 47B47, 47L30.

Keywords and phrases: Derivations, Jordan derivable linear maps, Hilbert spaces.

\section{REFERENCES}

[1] E. Christensen, Derivations of nest algebras, Math. Ann. 229 (1977), 155-161.

[2] I. N. Herstein, Jordan derivation on prime rings, Proc. Amer. Math. Soc. 8 (1957), 1104-1110.

[3] J. Hou, X. QI, Additive maps derivable at some points on J-subspace lattice algebras, Linear Algebra Appl. 429 (2008), 1851-1863.

[4] M.-Y. JiAO, J.-C. Hou, Additive maps derivable or Jordan derivable at zero point on nest algebras, Linear Algebra Appl. 432 (2010), 2984-2994.

[5] W. JING, On Jordan all-derivable points of B $(H)$, Linear Algebra Appl. 430 (2009), 941-946.

[6] W. JING, S. LU, Generalized Jordan derivations on prime rings and standard operator algebras, Taiwanese Journal of Mathematics 7 (2003), 605-613.

[7] C. Pearcy, D. Topping, Sums of small numbers of idempotents, Michigan Math. J. 14 (1967) 453-465.

[8] X.-F. QI, J.-C. Hou, Characterizations of derivations of Banach space nest alegbras: All-derrivable points, Linear Algebra Appl. 432 (2010), 3183-3200.

[9] J. ZHU, C. XIONG, All-derivable points in continuous nest algebras, J. Math. Anal. Appl. 340 (2008), 845-853. 